DOI: $10.20472 / S S .2019 .8 .2 .002$

\title{
WOMEN LEADERSHIP IN HIGHER EDUCATION IN SAUDI ARABIA
}

\section{LAMA ALGHOFAILY}

\begin{abstract}
:
Gender equality is considered as a challenge that human society need to overcome in order for its long term sustainability. This paper looks at the factors that may be barriers to women rise to leadership in Saudi higher education institutions. Education sector is by far the largest employer for Saudi women and is one of the sectors where women should expectedly face minimum barriers to rise to leadership. Saudi government has recently introduced many reforms (under the 2030 vision) which are expected to have a direct impact on women empowerment. This research is one of the very few researches conducted into the impact of the 2030 vision on women leadership in Saudi Arabia.
\end{abstract}

Data for this research was collected using semi structured interviews with Saudi women working in Saudi higher education institutions. Data was thematically analysed. Results indicate that Saudi women have faced a number of barriers in rising to leadership positions but the 2030 vision is expected to lower many of these barriers. Furthermore, this research finds that using direct references towards women empowerment in government policy statements is likely to lead to more effective outcomes in lowering barriers to women's rise to leadership in the Kingdom.

\section{Keywords:}

Women Leadership, Higher Education, Saudi Arabia

JEL Classification: 123

\section{Authors:}

LAMA ALGHOFAILY, University of Lincoln , United Kingdom, Email: lama85@hotmail.co.uk

\section{Citation:}

LAMA ALGHOFAILY (2019). Women Leadership in Higher Education in Saudi Arabia. International Journal of Social Sciences, Vol. VIII(2), pp. 14-32., 10.20472/SS.2019.8.2.002 


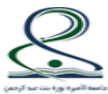

\section{Introduction}

Leadership is a concept which marginalises women directly or indirectly (Blackmore, 2010), with education sector being no exception (Blandford et al. 2011). Higher Education (HE) has seen a six-fold increase in the enrolment and participation levels of women across the globe in the last 40 years (Morley, 2013; Leathwood and Read, 2009). However, these numbers are not translated into effective representation in leadership roles in higher education establishments, with Beer (2013 in Morley, 2013) observing that the majority of academic leaders are male.

Saudi Arabia is one country which has often been highlighted in such a debate because of its gender segregated culture and poor performance on gender gap index despite being considered somewhat richer country on GDP scale. While Saudi Arabia has one of the best female education statistics in the world, the numbers do not reflect in its low position in women employment and women empowerment. In particular Saudi Arabian women are seen as being deprived of economic and leadership opportunities.

While most of the past researchers have shed some light on the issue but those researches were conducted at a time when Saudi Arabia did not undertake any radical and sweeping reforms, such as the recently announced 2030 vision, to rectify the situation. The 2030 vision is aimed at gradually eliminating such barriers. This paper looks at the current and future state of women leadership in Saudi higher education institutions.

The main aim of this paper is to explore the Saudi women's perception of the current and future state of the barriers affecting women leadership in Saudi higher education institutions.

The key research questions for this paper are:

- What are the key cultural, organisational and personal barriers that women face in achieving leadership positions in Saudi higher education institutions;

- How is the 2030 vision likely to affect the cultural, organisational and personal barriers that women face in achieving leadership positions in Saudi higher education institutions.

\section{Women Leadership in Higher Education of Saudi Arabia}

Abalkhail (2017) looked at women leadership in Saudi higher education institutions and found that despite comparative better qualifications and experience than their male counterparts, women were less preferred choice for leadership roles. Almansour and Kempner (2016) found that women have to overcome several personal challenges and have to exhibit extraordinary commitment to overcome personal challenges in their path to leadership; for example, travelling to conferences despite the cultural and familial restrictions. Al-Asfour et al. (2017) highlighted several barriers for women attempting to rise to leadership positions such as lack of freedom to travel, gender stereotyping, restricted growth opportunities, poor consideration for work life balance etc. Such issues create both 
endogenous and exogenous challenges for women seeking leadership positions (Alsubaihi 2016). Policy makers must consider Work-life policies and flexible work arrangements for academics (Boohene, Charles and Agyemang, 2012).

As the part of the Kingdom's developmental plans, the education and employment for the women in Saudi Arabia is being vigorously promoted (Ministry of Higher Education, 2010). Saudi government has undertaken some initiatives to give women more representation at higher levels but these initiatives are mainly focused on the field of politics (Varshney, 2019; Jarbou, 2018). However, researchers believe that women are still far away from achieving equality. Studies have identified that the number of the women in management and leadership position in Saudi Arabia was 3.2\% in the year 2017 and 7\% of the women are in legislative and managing positions (Account Ability, 2017). This evidence informs that gender diversity in Saudi Arabian board rooms is still very low.

Higher education institutions are key institutions for advocating gender rights in society (António et al. 2013).Several researchers have analysed state of women leadership in the higher education of Saudi Arabia, but this literature significantly lacks the perspective of the women leaders in higher education (von Alberti-Alhtaybat, \&Aazam, 2018). Although, it is known that barriers to higher education and leadership position still exist, very few studies have focused on analysing that what could be the significant barriers and what could be the motivations that encourage women to seek leadership positions in higher education of Saudi Arabia (Longman, 2018). Saudi women are allowed to seek jobs or employment in the education system. Saudi Arabian education system is dominated by women educators, but how they perceive their position and their responsibilities as educators and organisational leaders, is to clearly known (Elliott \&DeFrank-Cole, 2018).

Findings of the study conducted by von Alberti-Alhtaybat, \&Aazam (2018) has identified that there are three different concepts that affect the Saudi Arabian women leadership in education. These concepts can have the negative as well as the positive influence over the leadership and its effectiveness among these women. These concepts include, experience and expectations from the leadership position, challenges of managing the work-life balance and differential treatment at the workplace (von Alberti-Alhtaybat, \&Aazam, 2018). Different female leaders have different experience in their leadership positions, secondly they have the dual pressure of managing the work life balance and their positions are also significantly influenced by the differential treatments (Abouammoh, 2018). One of the interesting finding that von Alberti-Alhtaybat, \&Aazam, (2018) have presented is that most of the women employees or leaders working in the field of higher education have experienced unresponsiveness and lack of support from the fellow female leaders, which can be new insight to the barriers that women face towards achieving leadership positions.

Saudi women have a good share of positions in the education sector. Princess Nora bint Abdul Rahman University is the first all female university (Al-Sudairy, 2017). However, apart from King Abdullah's University of Science and Technology women face gender segregation in the education sector. Since the field of education is segregated by gender and the women make a good proportion of the education faculty, it also displays significant 
chance of achieving the leadership position in higher education (Varshney, 2019). However, despite the rise in women employees in Saudi HE sector, Saudi women have not been able to achieve the leadership or senior management position in considerable number (Elliott\&DeFrank-Cole, 2018; Al Alhareth et al. 2015).

According to the statistics provided by the Ministry of Education (2019), only one woman has achieved the highest leadership position as the director of the University in Saudi Arabian higher education. 12 women are in the position of Vice President and 61 are working as Dean and 228 women have been able to achieve the position of Deputy dean of faculty in Saudi Arabian university(Neubauer\& Kaur, 2019). The positions that are offered to the women are mainly for the campus specially dedicated for women. Some of the universities in Saudi Arabia are just for the females, therefore, the positions of dean or deputy dean are only awarded to the women with limited decision making control and power (Neubauer\& Kaur, 2019). However, studies have identified in some roles women are provided with more power and responsibility then men. For example, according to the study of Almaki, Almaki, \&Silong (2016), the women are preferred for the role of the dean and deputy dean, as it is believed some functions can be effectively carried out by women rather than by men, such as the role of dean of community service, art \& design etc. Therefore, the evidences inform that women are now achieving the higher positions of the dean and deputy deans which were earlier given to men. Yet, the number and participation of the Saudi women in higher education leadership is still very limited with limited powers (Abalkhail\& Allan, 2015).

\section{Barriers to Women Leadership}

Women in Saudi Arabia experience similar barriers and obstacles that many other women around the world face to achieve the senior leadership positions (Sobehart, 2015). Barriers affecting women's rise to leadership can be mainly categorised as cultural, organisation and personal barriers.

\section{Cultural Barriers to Women Leadership in Saudi Arabia}

The conservative orientation towards the females in Islam is mainly considered as the contribution of the culture and customs of the tribal communities that prevailed in the Arabian Peninsula long before when Islam was established (Al-bakr et al., 2017). Conservative religious scholars in Saudi Arabia, who have always encouraged women to remain at home, use time-honoured fashion of interpretation of the holy book "regardless of globalization, the media revolution, the social transformations, the demographic shifts and the economic waves of affluence that the country has passed through over the last few decades" (Alotaibi, Cutting, \& Morgan, 2017, p. 32).Women who go out and strive to excel professionally are often viewed as contrarian to the moral role by these scholars and people who believe in their interpretation. Institutions dominated by conservatives see women's career advancement and higher education as undermining their patriarchal domination and also seen as challenging their control of power (Arar\&Oplatka, 2016).

There are mainly two major restrictions on the women associated with the Islamic family law these factors and these restrictions are limitations to women's mobility and lack of free choice for education and occupation (Alexander, 2013; Moghadam, 2009). Strict gender 
segregation at workplace also limits the Saudi women's ability to acquire the leadership positions (Abalkhail\& Allan, 2015). This also limits their abilities and capabilities to acquire new skills, get access to new opportunities for their professional and social advancement (Abalkhail, 2017).

\section{Organizational Barriers and Women Leadership in Saudi Arabia}

Several organisational barriers have been identified that affect leadership progression of Saudi women. One major organizational barrier is that women in Saudi Arabia receive very few opportunities and growth and development in the workplace (Al-Asfour et al. 2017; Kattan, et al. 2016). Not only are women restricted to work in certain sectors such as education, even within such sectors, the organizations have very discriminatory appointment procedures and promotion options, traditional attitude of the male bosses towards the women working in the organization (Almunajjed, 2010).

At workplaces and in many cases even at home, women are excluded from strategic decision making hampering their ability to acquire decision making capabilities as well as affecting their confidence in their leadership abilities (Abalkhail, 2017). The centralised governing system practiced commonly among Saudi organisations centralises the power at the top position, which is often occupied by male.Al-Ahmadi (2011), states that "probably the single most important hurdle for women in management in all industrialized countries is the persistent stereotype that associated management with being male" (p. 152). Indeed, some of the other organizational barriers that women have to face are the male dominated sector, the resistanceof the male towards women in management, lack of appropriate policies and legislations for encouraging the participation of women in organizational management (Kattan, et al. 2016).

There are also various challenges associated with the structural factors that affect the women leaders. These structural factors occur due to management and organizational practices, where the women are provided with very little opportunities to hold some power (AlAhmadi, 2011). According to Hodges (2017) the power offered to the women are limited in organizations, therefore, they are limited to the lower management positions.

Organizational barriers also include the constant interference of men and restriction of freedom for decision making (Hodges, 2017). Studies have found that there have been many policy enhancements and provisions made for taking the female oriented measure at the workplaces and in employment in Saudi Arabia. Therefore, the private sector of the country has started realizing the significance of female participation at workplaces (Arar, \&Oplatka, 2016). Despite positive improvement made by the government and policy makers, women are poorly empowered and Saudi Arabia still scores very poor in terms of women participation in the workforce and in terms of career advancement (Gorney, 2016) largely due to the structural challenges (Thompson, 2015). The three main identified structural challenges are centralization of the decision making process lack of women participation in the formulation of strategies and lack of authority are the most significant structural challenges. Lack of confidence in their leadership skills, managerial efficiency, and capabilities could be factors contributing to structural barriers (Al-kayed, 2015). 
Empowerment of women at the workplace is a very significant component of contemporary leadership practices (Al-Asfouret al. 2017). However, the centralized system in Saudi Arabia, do not indicate many opportunities of women empowerment (Smith \&Abouammoh, 2013) as Saudi women may not be as authoritative in management due to the cultural environment of Saudi Arabia which allocates more authority to men. Lack of communication in organizations resulting for gender segregation also widens the gap between the women sections and senior leaders (Al-Ahmadi, 2011, p. 153). As a result the issues that they need to highlight are often overlooked as they do not have direct representation at decision making levels.

\section{Personal Barriers and Women Leadership in Saudi Arabia}

The personal barriers to the career advancement of women are significantly higher than organizational barriers (Shabbir, Shakeel, \&Zubair, 2017). The social circumstances and women's personal experiences in the restricted society often affect their leadership behavior and skills. Women become incapable to exercise their leadership role effectively because of poor self-confidence, fear of taking responsibilities and difficulty to maintain the balance between the family obligations and professional responsibilities (Albakry, 2016;Tlaiss, 2014). Women in Saudi Arabia also have the sense of being isolated, when they reach the administrative positions because the structural and organizational challenges often isolate the women departments. Women in Saudi Arabia also have the increased mental and psychological pressure, because they are often subjected to social, professional and cultural pressure (Marinakou, 2014).

Low self-efficacy is a major barrier that restricts women to achieve better positions in their career (Tlaiss, 2014) as their status mainly remains limited to the domestic responsibilities (Marinakou, 2014). Lack of self-confidence is a significant factor that results in fear from taking the professional responsibilities among women. Social pressure and traditional and culture problems prevent the development of the proper leadership attitude and values among women (Al-Ahmadi, 2011). Another problem associated with personal characteristics of the women is the problem of role conflict, as the women face problem in balancing professional and personal life. This is mainly due to the lack of the structural support within the organizations that creates difficulty for women in fulfilling the family obligations and professional demands (Kattanet al. 2016). Another theme identified in terms of personal barriers is the feeling of suffering and frustration, which occurs due to the increasing pressure of dual roles and sense of marginalization that affects their personality. Women often feel themselves to be inferior, because they have been brought up in the environment, where men are considered as superior and women are supposed to be passive and submissive (Alotaibi et al. 2017). Therefore, there is a mix of many personality traits that impact women leadership and ability to acquire the senior management and leadership positions. It has been found that lack of information and inclusion of women results in lack of managerial skills and information that are required to exercise leadership.

The women who aspire to be leaders in Saudi Arabia have to overcome the childhood socialization that had significantly discouraged and suppressed the development of some important leadership qualities. Kattan et al. (2016) also state that "a popular perception of the maleness of leadership both of which tangibly reduce the chance she will be judged 
qualified", which means the association of masculinity with leadership affect chances of women being accepted as leaders.

\section{Research gaps and contribution}

While some research has been conducted on understanding the barriers that affect women's progression to leadership in Saudi Arabia, further research is required to explore the impact of new policies and initiatives. Saudi Arabia is in a state of transition from conservative to liberal culture and this is leading to significant changes in these barriers as well. The announcement of the 2030 vision is expected to relax many of these barriers and it must be seen if the women leaders are expecting any realistic change coming out of this vision. In addition, the royal decrees announced in 2017 for removal of ban on women driving and relaxation of male guardianship laws are also expected to cause significant changes which is expected to affect women's progression to leadership. However, extremely scarce literature exists which has looked at the impact of these recent changes on women's progression to leadership in Saudi Arabian HE institutions. This makes this research comparatively more relevant and accurate in present context.

Government has announced some new initiatives such as 'Saudi female leaders' and 'The National Transformation Plan 2020' (Saudi Vision 2017) which directly aims to increase women participation in leadership by 2020. It includes several initiatives such as improved training, reforms and legislation etc. to boost women's skills, performance and representation in leadership positions. It is extremely important for the impact of these initiatives to be considered on state of women leadership in the Kingdom merely because the significant changes they have brought to women leadership in Saudi Arabia (Alsubaie and Jones, 2017). Research also needs to address the issue of suitability of these initiatives. In this regard it needs to be identified as what kind of policies will be more effective in Saudi context and whether the changes brought so far can be expected to bring any meaningful long term change. How women construct their identities after these initiatives have been announced must also be explored through subjective experiences of women towards the changes in their society, family, workplaces etc. (Alsubaie and Jones, 2017). This research aims to fill these gaps.

\section{Methodology}

\section{Research paradigm}

This research is based on interpretivist epistemology and subjectivist ontology. The choice is based on the chosen nature of the research as evident with the research questions. The aim is not to generalise here but to identify range of barriers that affects the Saudi women as of now. This research will also explore the different perspectives on different barriers through anecdotal evidence provided by the respondents. Also, there is no concrete and verifiable data on how the 2030 vision is expected to affect these barriers. Instead respondents will be asked about the changes they have witnessed since the announcement of the 2030 vision and their perception of future in light of these changes. Finally this research seeks to identify the kind of policies that the Saudi government need to enact in order to overcome these barriers. Once 
again, such policies may not exist and hence the impact of such policies will be merely perceptual and speculative.

Since this research is based on subjective, perceptual and somewhat speculative information hence interpretivist epistemology and subjectivist ontology were adopted for this research.

\section{Data collection method}

The exploratory nature of the research questions warranted the use of qualitative methodology. Data was collected using semi structured interviews. The perceptual, contextual and subjective information required for this research can only be obtained through semi structured interviews where individuals can share their views and some anecdotal evidence based on their own personal experiences.

\section{Sampling}

Non probability sampling was adopted for this research because the sample selected was very specific- experienced women staff members from Saudi universities. In total 15 semistructured interviews were conducted with staff members female universities. Currently, women are only employed in female universities and hence the focus of his research was the female universities in Saudi Arabia. The sample included only female respondents with at least 10 years experience. Including females, with a minimum of 10 years, experience ensured that the respondents had full knowledge of the barriers before and after the announcement of 2030 vision. Male respondents were excluded from this research because due to gender segregation males are less likely to provide accurate data required for this research.

\section{Data analysis}

Thematic analysis technique was adopted for analysing the data. The thematic analysis technique has been used by several researchers in qualitative researches focused on Saudi women in leadership (see, for example, Hodges, 2017; Al-Asfour et al. 2017; AlDoubi, 2014; Gazzaz, 2017). Thematic analysis was considered useful for this research because the researcher was unaware of all the potential themes that it was going to discover. Furthermore, the focus was more on the latent content and not as much on the manifest content.

\section{Findings}

Organisational barriers: Lack of Leadership training was mentioned as one of the key organisational barriers to leadership by the respondents. Respondents suggested that women are not given sufficient leadership training that will equip them to prepare for leadership positions. When asked about whether they have received any leadership training most respondents suggested that they have received some training but complained that the training was insufficient or inadequate. The lack of leadership training could be to do with lack of opportunities itself. 
Lack of decision making opportunities was mentioned as another organisational barrier. Respondents mentioned that women do not get to make most high level decision in their organisations.Respondents suggested that women should be given decision making responsibilities from early stages in order to prepare them as they gain experience.

Respondents also cited that there are insufficient opportunities to obtain required qualifications. Indeed, one of the ways in which academics can boost their profile and recognition the global community is through participation in international conferences and seminars where they can share their research with other peers from around the world. But women are not given the same kind of support for such activities as compared to men.

Respondents strongly suggested that all the indicators such as poor support for obtaining qualifications and lack of leadership training indicate reluctance to consider women for top positions. Most respondents agreed that there is no much effort in women development for leadership and that women are unlikely to be considered for top position so it does not even make sense.. Respondents suggested that unless organisational policies change to given equal, unbiased and fair opportunities to individuals without taking their gender into consideration such policies will continue. Respondents suggested that lack of interest is not only from the management but also from women staff members because they feel that despite their best efforts nothing will come out of it.

Some respondents commented that giving women little credit for achievements is one of the organisational barriers.

Lack of clear promotion criteria and lack of connections were two of the organisational barriers that seem to affect women in pursuit of leadership. Respondent who disagreed with the connections issues suggested that connections may play a role in accession to leadership but this is not a barrier for capable people. Overall the responses indicate that while connections may not explicitly assist in reaching higher positions but it does provide certain privileges which individuals can use to their advantage.

In addition to lack of clear promotion criteria, respondents also indicated that there is stricter/biased promotion policy for women. This was highlighted in the comments where respondents indicated that qualification criteria for promotion are much lower for men as compared to that for women. This means that women have to work extra hard in order to get promotion. According to some respondents more leadership positions are created for men than women. Despite there being larger number of women in Saudi higher education this does not reflect the number of top positions being offered to them.

Women not only suffer from lack of recognition and growth opportunities but also from one of the most critical components of top level promotions i.e. connections. Lack of connections with top level decision makers was cited as another organisational barrier. Some respondents suggested that to reach to the top people need connections and women often do not have these connections as they do not engage with influential people.

Women face challenges in not only generating support from top level connections but also suffer from disfavouring and uncooperative behaviours of the peers and subordinates. 
Many other respondents commented that professional jealousy is often a barrier for women at workplaces. Respondents suggested that jealousy often affects their ability to cooperate which affects not only their ability to grow but also their ability to contribute to the growth of others.Not all respondents agreed with poor and uncooperative behaviour of colleagues. Some respondents actually indicated that they received good support from their colleagues.

Respondents highlighted lack of authoritative power as one of the key organisational barrier affecting women's progression to leadership. In this case respondents suggested that women often make low level decision and do not have sufficient power to take authoritative decisions. Their decisions can easily be disputed and overturned. This affects their confidence as well as willingness to take meaningful decisions.

According to the respondents women find it difficult to manage the workload and burdensome administrative task. One of the respondents who disagreed with workload and burdensome administrative task being a barrier suggested that people who aspire $t \mathrm{~b}$ leaders should and often do know what it involves.

Many respondents suggested that poor work-life balance is one of the reasons why women either do not seek top positions or are not considered or top positions. This is quite common in Saudi Arabia where women are traditionally considered for familial roles rather than professional roles and hence even when they play professional roles they are supposed to prioritise familial responsibilities.

Many respondents indicated that even in cases when women do not face any familial pressure they may suffer from inner guilt that they are probably ignoring their family for their professional aspirations. Respondents indicated that social upbringing for Saudi women is such that they feel being a mother and wife as their primary duty and guilty if they are not fulfilling it to the best of the expectations of the family members. In this respect the poor work life balance may be perceptual rather than factual.

Respondents suggested that more workload and responsibilities often deter some potential candidates from seeking top position. This means that some women may deliberately slow down their progression so in order to minimise the workload and responsibilities. Organisational barriers therefore not only affect women's ability to reach the top but also affect their desire and motivation as realising the difficulties involved or very low probability of success in this endeavour many women tend to divert their attention and focus towards other aspects of life.

Preference for masculine management style was also cited as an organisational barrier by respondents. Saudi society is a highly masculine society as per the Hofstede cultural index. In such a culture feminine leadership traits are not highly prized. For example, in masculine societies, conflicts are often resolved through force while in feminine culture these are solved through negotiation. Also high power distance index culture of Saudi Arabia means that the leaders must be authoritative. However, there is a need for women leaders precisely because of their management style which may not comply with the general view of leadership in Saudi Arabia but may be more suitable in higher education settings. 
Cultural barriers: Cultural barriers are one of the most commonly cited reasons for glass ceiling in Saudi Arabia. One of the factors mentioned was the negative perception of women leadership style/approach. Respondents indicated that in Saudi society women are generally not considered to be good leaders and decision makers.

Respondents agreed that poor leadership of Saudi women may be somewhat true but they suggested that it is not because they lack capabilities but that over time period, through the cultural practices these skills have been eroded to a great extent.In addition, to negative perception of women leadership, respondents also hinted towards negative perception of women in leadership being one of the cultural barriers in women leadership. According to the respondents, women who work towards getting leadership positions are often seen as immoral, non-familial individuals who are pursuing professional success at the cost of their moral responsibility of looking after the family. According to the respondents while men face challenges to become professionally successful, women tend to face pressure to give up their professional ambitions in order to focus more on the family.

It is quite interesting because broadly speaking there is a positive perception about women education in Saudi Arabia. Yet, despite being so open about women education the society seems closed and apprehensive towards women employment.

Another key cultural issue which has been raised in many contexts in Saudi Arabia is lack of freedom for women. For example, most women suggested that when it comes to making career choices they have to always keep others in mind even if they have really good opportunities. Most of the respondents agreed that in terms of freedom there is a lot that could be done to improve the situation. The problem is that lack of freedom may permeate into the minds of individuals where they may assume these to be their natural roles in the society as followers.

The tribal traditions, enacted for life in old times have continued in modern times. These tribal traditions have affected the state of women significantly as these not only affect the women but also government's capacity for reforms in this direction.

One of the tribal traditions that was mentioned by many respondents was mehram, a practice in which females require a written permission from their legal male guardian for many things. According to the respondents this is the tribal practice with no reference to shariah but is still practiced by law even though this may not be relevant today. As mentioned before such practices lead to subservient attitude of females which affects their mindset.

One of the most commonly cited cultural barriers mentioned by respondents were family norms/ responsibilities. In Saudi society women are considered suited to familial roles and are expected to compromise with their professional ambitions for playing their familial roles. Women not only face lack of support at organisational level but also at family level. Respondents indicated that lack of family support affects women quit seriously. Respondents indicated that for most of the women family pressures to prioritise familial responsibilities is one of the key stumbling blocks. 
As per the respondents views the stereotyping of women's role in the society is one of the reasons why some women do not even dream of going big. However, there is positive change in the society in this respect. Some of the respondents denied that women suffer due to lack of family support.According to these respondents, things have starting to change with many men preferring working wives.

Personal barriers: Among the personal barriers the first and foremost barriers that the respondents highlighted was the lack of confidence to lead. According to the respondents, due to years of playing subservient roles to males, Saudi women have over the time lost the confidence to lead. Respondents mentioned words like fear, reluctance, hesitation which all indicate that women lack the confidence to lead.

According to some respondents women feel safer in their role as academics as they are confident that they can play this well. However, they may not have same level of confidence when it comes to leadership roles. Most of the respondents expressed similar views that women are likely to be less confident because they have not yet led professional organisations at the top.

Another personal barrier highlighted by the respondents was the lack of motivation to lead. Many respondents suggested that women tend not to be too competitive because probably they have been groomed to be more accommodating since childhood. They do not see themselves as leaders. One respondent, however, disagreed that there is a lack of motivation to lead among women. There was, thus, a divide amongst the respondents on whether women are motivated to lead or not. On closer inspection it seems that those in senior positions tend to disagree that women lack motivation to lead while those in junior positions indicated the lack of motivation.

Another factor similar to lack of motivation cited by respondents was Lack of interest in leading. According to some of the respondents many women are simply not interested in leading because of reasons such as fear to have insufficient time for family.

Thus, many respondents indicated that women make a personal choice of work life balance. They tend to forego leadership opportunities as this would require them to ignore their family life as well as leave no time for personal relaxation.

Lack of interest could be because of anticipation of the social and familial pressures as well. Societal pressure was cited by many respondents as one of the key pressures that they feel at all stages of their lives especially when they are reaching towards the top because this is when they get busier. Some respondents suggested that even if the women are balancing their family and professional lives well their families behave as if they are being irresponsible mothers. This leads to a sense of guilt among women professionals.

Respondents also cited lack of managerial training and experience as one of the key personal barriers. Respondents suggested that because of lack of professional training women tend to feel underprepared to lead. Most of the respondents disagreed that women lack capability to lead. In fact some respondents even went on to report that they felt offended by the question itself. According to these respondents, on the contrary women aspire to lead and 
that they have a lot to contribute through their different leadership style. According to some respondents, capability to lead is not gender specific.

Impact of 2030 vision: Respondents sounded optimistic about the changes being brought under the 2030 vision. 11 out of the 15 respondents sounded optimistic about the 2030 vision and suggested that the new vision is likely to have profound and positive impact on the current situation regarding women leadership. Although 7 of these respondents agreed that the current changes in itself are not enough but they indicated that these are signs of things to come. Remaining 4 respondents suggested that the changes introduced will lead to a domino effect causing widespread changes. Out of the respondents who disagreed with effectiveness of the 2030 vision, 3 suggested that the current level of changes are insufficient and lot more needs to be done in order resolve the situation while 1 respondent suggested that this is nothing more than an eyewash.

According to the respondents women in the kingdom seem motivated by the announcement of changes in the 2030 vision. Some respondents exhibited excitement with the appointment of the first women ambassador. According to them such high profile appointments are likely to boost the image and morale of women in the Kingdom. Some respondents, however, disagreed with the 2030 vision bringing in any large scale changes. According to them the male dominated structure of global society is unlikely to change soon and such changes must originate at social level rather than through political reforms.

Except one respondent other respondents more or less agreed that if implemented properly the 2030 vision has a strong possibility of bringing in the desired changes. According to the respondents the major impact of the 2030 vision has been to provide more public space to women and remove the hypothetical barriers that affected social and professional lives of Saudi women. In views of the respondents, the changes brought in by the 2030 vision are likely to bring a change in attitudes which will lead to other constructive changes for the role of women. Respondents also believed that the changes will be gradual and will become effective only if the reforms are sustained over a long period of time.

Most of the respondents agreed that the government need to announce and implement more programs directly aimed at women empowerment. One respondent, however, suggested that mere words will not help and government should look to prepare concrete and achievable plans for women. Respondents highlighted issues such as role models as being of critical importance and suggested having genuine and a number of role models instead of token presence of some already powerful women in top positions. According to them, while presence of women at top helps but what is lacking is the story behind the rise of these women because they did not struggle or compete like unprivileged person.Thus, the respondents may be suggesting that something more meaningful need to be done in this regard.

Policy reforms: Respondents highlighted several policy solutions for the problem. Interestingly respondents suggested that the most critical barriers that policy makers should look to resolve are the organisational barriers. According to the respondents, while other 
barriers affect women's personal choices, organisational barriers affect even those women, who are otherwise ready to take on leadership roles.

According to the respondents organisational barriers are entirely in the hands of the policy makers and are therefore resolvable through right policy making. On the other hand, other barriers are somehow linked to organisational barriers and will take long time to resolve. For example, reducing cultural barriers would require change in mindset, perspectives and behaviour of people and this is unlikely to happen overnight. However, removing organisational barriers could trigger the process of sustained reforms. Respondents hinted that changing perception of women such as making them more confident of their abilities, role of women in families and society etc. will take time. However, removing organisational barriers will fast track process because it is likely to improve their chances of success.

In opinion of the respondents, once the organisational barriers are removed, women will push through the glass ceiling and those who manage to do this will motivate others. This means that organisational barriers will create a more level playing field for women and then women will be able to make more independent choices regarding their professional ambitions.

Some respondents suggested that they have received leadership training but did not find it much useful. Some other respondents suggested that leadership trainings are provided just to meet the budget and planning targets but the programs are of little help. Respondents commented that job roles should be redesigned so as to give women some decision making responsibilities from right early in their careers. This will boost their leadership skills, confidence and motivation as they grow in their career. Furthermore the training programs should be designed and developed with full consultation from the staff and their feedback should be obtained to evaluate the effectiveness of programs.

When talking about the role models the respondents stressed on having genuine and respected role models rather than having some influential individuals appointed on top positions. The role models and their stories need to inspire individuals and in this respect developing role models of women who started off their careers at lower levels and with time and effort rose to levels is likely to be more inspiring for women.

Respondents also spoke about giving more media coverage to achievements of women will highlight the progress that women are making. For example, when the top ministers recognise the achievements of women even through simple tweets, it acts as motivator for other women.

\section{Conclusion}

This research highlighted several barriers that continue to affect omen's rise to leadership in Saudi HE system. Respondents did express optimism in light of the steps taken by the government since the announcement of the 2030 vision. Current steps at breaking away from the tribal system and giving more public space to women is likely to provide long term benefits. 
The public perception of women's sole role as homemaker has been one of the barriers that has affected women in several ways; it not only created negative image of women seeking professional growth but has also affected women's own choice regarding work life balance.

Furthermore, lack of decision making opportunities for women professionals especially at earlier stages in their careers impedes development of leadership capabilities which also affects their motivation and interest to lead at later stages. A gradual and systematic approach to leadership development is required which means more decentralised organisation structure must be adopted in HE institutions.

Public acknowledgment of the achievements of women especially by the top political leadership is likely to motivate women especially in breaking down their stereotyped self image.

The 2030 vision has addressed some of the barriers but a direct and wider set of actions are required to provide desirable results. Giving women genuine role in policy making will help the government make more effective policies towards women empowerment. Saudi government need to take additional measures such as providing leadership training, giving more decision making powers to women in order to boost their confidence and status. Having role models and leadership training and development are likely to be positive steps in the gradual elimination of the cultural barriers to women leadership at the general level.

In summary, respondents indicated that government must consider the following when making policies regarding women:

- Be explicit in what it wishes to achieve vis a vis women empowerment.

- Be direct in approach rather than using a covert approach to women empowerment.

- Look at par distribution of power from early stages to equip women for leadership roles.

- Look at taking genuine steps rather than symbolic steps.

- Increase recognition of achievements of women at national level.

- Twitter can be a powerful tool for the ministers to acknowledge and highlight the achievements of women. 


\section{References}

- Abalkhail, J. M., and Allan, B. (2015). Women's career advancement: mentoring and networking in Saudi Arabia and the UK. Human Resource Development International, 18(2): 153-168. https://doi.org/10.1080/13678868.2015.1026548

- Abalkhail, J.M. (2017). Women and leadership: Challenges and opportunities in Saudi higher education. Career Development International,22(2): 165-183. https://doi.org/10.1108/CDI-03-2016-0029

- Abouammoh, A.M. (2018). The Regeneration Aspects for Higher Education Research in the Kingdom of Saudi Arabia. In Researching Higher Education in Asia (pp 327352). Springer, Singapore. https://doi.org/10.1007/978-981-10-4989-7_19

- Abukudair, E. (2012). The Challenges Facing Women Leaders in Higher Education Institutions in the Kingdom of Saudi Arabia. Saudi Journal of Higher Education 7: 87-124.

- Account Ability. (2017). Women In Management and Leadership In The Kingdom of Saudi Arabia. Retrieved from: https://www.accountability.org/wpcontent/uploads/2017/06/AA-GW-Final-report-English.pdf

- Al Alhareth, Y., Al Dighrir, I. and Y. Al Alhareth (2015). Review of Women's Higher Education in Saudi Arabia. American Journal of Educational Research 3: 1015. https://doi.org/10.12691/education-3-1-3

- Al Ghamdi, A. M. (2016). The Empowerment of Academic Women Leaders at Saudi Universities and Its Relationship to Their Administrative Creativity. Doctoral dissertation, Western Michigan University

- Al-Ahmadi, H. (2011). Challenges facing women leaders in Saudi Arabia. Human Resource Development International 14: 149-66. https://doi.org/10.1080/13678868.2011.558311

- Al-Asfour, A., Tlaiss, H.A., Khan, S.A. and R. James (2017). Saudi women's work challenges and barriers to career advancement. Career Development International 22: 184-99. https://doi.org/10.1108/CDI-11-2016-0200

- Al-bakr, F., Bruce, E. R., Davidson, P. M., Schlaffer, E., and Kropiunigg, U. (2017). Empowered but not equal: Challenging the traditional gender roles as seen by university students in Saudi Arabia. In FIRE: Forum for International Research in Education 4(1): 3. https://doi.org/10.18275/fire201704011083

- Albakry, A. H. (2016). Voices of women leaders in corporate institutions in Saudi Arabia, Doctoral dissertation, University of San Francisco.

- AlDoubi, S. H. (2014). Road to leadership: experiences of Saudi women in higher education, Doctoral dissertation, Colorado State University. Retrieved from: https://dspace.library.colostate.edu/bitstream/handle/10217/82578/AlDoubi_colostate _0053A_12296.pdf?sequence=1

- Alexander, N.H., (2013). Saudi Arabia female students' perception of effective female leaders. Advancing Women in Leadership, 33:142-150.

- Al-kayed, L. (2015). Leadership challenges for women managers in public universities in Saudi Arabia. Global Journal of Human-Social Science Research. 
- Almaki, S. H., Almaki, R. H., and Silong, A. D. (2016). The Path of Leadership Experience of Muslim Women Leaders in Higher Education. International Business Management, 10(15): 2967-2972. https://doi.org/10.5901/jesr.2016.v6n3p75

- Almansour, S. and K. Kempner (2016). The Role of Arab women faculty in the public sphere. Studies in Higher Education, 41: 874-86. https://doi.org/10.1080/03075079.2016.1147723

- Almunajjed, M. (2010). Women's employment in Saudi Arabia: A major challenge. Booz and CO, 2-13.

- Alomair, M. O. (2015). Female leadership capacity and effectiveness: A critical analysis of the literature on higher education in Saudi Arabia. International Journal of Higher Education, 4(4): 81. https://doi.org/10.5430/ijhe.v4n4p81

- Alotaibi, F., Cutting, R., and Morgan, J. (2017). A Critical Analysis of the Literature in Women's Leadership in Saudi Arabia. International Journal of Business Administration and Management Research,3(1): 29-36. https://doi.org/10.24178/ijbamr.2017.3.1.29

- Alsubaie, A., and Jones, K. (2017). An overview of the current state of women's leadership in higher education in Saudi Arabia and a proposal for future research directions. Administrative Sciences, 7(4). 36. https://doi.org/10.3390/admsci7040036

- Alsubaihi, S. I. (2016). Challenges for Women Academic Leaders to Obtain Senior Leadership Positions in Higher Education in Saudi Arabia, Ann Arbor: ProQuest.

- Al-Sudairy, H. T. (2017). Modern Woman in the Kingdom of Saudi Arabia: Rights, Challenges and Achievements. Newcastle-upon-Tyne: Cambridge Scholars Publishing.

- António, P., Rodrigues, A., Gonçalves, H., Marques, C., andDiniz, F. (2013). Gender equality in institutions of higher education: Diagnosis and action plan for an institution of higher education in the north of Portugal. International Journal of Teaching and Education, 1(1), 18-51.

- Arar, K., and Oplatka, I. (2016). Current Research on Arab Female Educational Leaders' Career and Leadership. In Challenges and Opportunities of Educational Leadership Research and Practice: The State of the Field and Its Multiple Futures. Information Age Publishing

- Blackmore, J. (ed.) (2010) Special issue: Disrupting notions of leadership from feminist post-colonial positions. International Journal of Leadership in Education, 13(1):1-6. https://doi.org/10.1080/13603120903242949

- Blandford, E., Brill, C., Neave, S. and Roberts, A. (2011). Equality in Higher Education: Statistical Report 2011. London: Equality Challenge Unit.

- Boohene, D., Charles, R.-O., \&Agyemang, M. (2012). A Critical Study on Work Life Balance. A Case of Teaching Faculty at Loyola Institute of Technology and Science, India and All Nations University College Ghana. International Journal of Social Sciences, I(1), 22-34.

- Dirani, K. M., Hamie, C. S., and Tlaiss, H. (2017). Leadership in Saudi Arabia: a multifaceted phenomenon. In Leadership Development in Emerging Market 
Economies (pp. 245-260). Palgrave Macmillan, New York. https://doi.org/10.1057/978-1-137-58003-0_14

- Elliott, J. D., and DeFrank-Cole, L. (2018). Recruiting women to work in the kingdom of Saudi Arabia: Challenges in leadership and cultural intelligence. SAGE Publications: SAGE Business Cases Originals. https://doi.org/10.4135/9781526440990

- Gazzaz, L., (2017). Renaissance of Saudi Women leaders' achievement, Doctoral dissertation, Brunel University London.

- Gorney, C. (2016). The Changing face of Saudi women. National Geographic February, 110-33.

- Hakem, L. (2017). The Challenges Saudi Women Face at Work. International Journal of Human Resource Studies, 7(1): 155-169. https://doi.org/10.5296/ijhrs.v7i1.10697

- Hodges, J., 2017. Cracking the walls of leadership: women in Saudi Arabia. Gender in management: an international journal, 32(1):34-46. https://doi.org/10.1108/GM11-2015-0106

- Jarbou, R. (2018). Know your enemy: the Saudi women's driving campaign from flyers and faxes to Youtube and hashtags. Feminist Media Studies, 18(2): 321-325. https://doi.org/10.1080/14680777.2018.1436902

- Kattan, M.M., Heredero, C.D.P., Botella, J.L.M. and Margalina, V.M. (2016). Factors of successful women leadership in Saudi Arabia. Asian Social Science, 12(5): 94. https://doi.org/10.5539/ass.v12n5p94

- Kelly, D. H., and Kelly, G. P. (2017). Women and higher education. In Women's Education in the Third World (pp. 199-219). Routledge.

- Le Renard, A. (2014). The politics of "unveiling Saudi women": Between postcolonial fantasies and the surveillance state. Jadaliyya. Retrieved from http://www.jadaliyya.com/pages/index/20259/the-politics-ofunveiling-saudiwomen_between-post

- Leathwood, C., and B. Read (2009). Gender and the Changing Face of Higher Education: A Feminized Future? New York: SRHE/Open University Press.

- Longman, K. A., Ante, A. And R. Remke (ed) (2018). Perspectives on Women's Higher Education Leadership from Around the World. Special Issue Published in Administrative Sciences, from https://www.mdpi.com/books/pdfdownload/book/795. https://doi.org/10.3390/admsci8030035

- Marinakou, E. (2014). The glass ceiling and women in management in the Middle East: Myth or reality. In: Finance, Economics, MIS and Global Business Research Conference, 11-12 December 2014, Miami, Florida.

- Ministry of Higher Education. (2010). Women in Higher Education: Saudi Initiatives and Achievements. Retrieved from: http://womeninscience.rasit.org/files/women_in_higher_edu_Saudi_Arabia.pdf 
- Ministry of Higher Education. (2013). Higher Education Statistics Centre, Saudi Arabia, Retrieved from: http://www.mohe.gov.sa/ar/Ministry/Deputy-Ministry-forPlanning-and-Information-affairs/HESC/Ehsaat/Pages/default.aspx

- Ministry of Higher Education. (2019). Higher Education. Retrieved from: https://www.moe.gov.sa/en/Pages/default.aspx

- Moghadam, F.E. (2009). Undercounting women's work in Iran. Iranian Studies, 42(1): 81-95. https://doi.org/10.1080/00210860802593932

- Morley, L. (2013). The rules of the game: Women and the leaderist turn in higher education. Gender and education, 25(1): 116-131.

- Morley, L., and Crossouard, B. (2015). Women in higher education leadership in South Asia: Rejection, refusal, reluctance, revisioning. Centre for Higher Education and Equity Research, University of Sussex, Retrieved from: https://www.britishcouncil.org/sites/default/files/british-council-women-highereducation-leadership-south-asia.pdf. https://doi.org/10.1080/09540253.2012.740888

- Mustafa, R. F., and Troudi, S. (2019). Saudi Arabia and Saudi Women in Research Literature: A Critical Look. Asian Social Science, 15(2). https://doi.org/10.5539/ass.v15n2p133

- Neubauer, D. E., and Kaur, S. (Eds.). (2019). Gender and the Changing Face of Higher Education in Asia Pacific. Springer International Publishing. https://doi.org/10.1007/978-3-030-02795-7

- Nydell, M. K. (2018). Understanding Arabs: A contemporary guide to Arab society. Nicholas Brealey.

- Shabbir, H., Shakeel, M. A., and Zubair, R. A. (2017). Gender stereotype, glass ceiling and women's career advancement: An empirical study in service sector of Pakistan, Retrieved from: http://bura.brunel.ac.uk/bitstream/2438/14736/1/FulltextThesis.pdf

- Smith, L., and Abouammoh, A. (2013). Higher Education in Saudi Arabia. London: Springer. https://doi.org/10.1007/978-94-007-6321-0

- Sobehart, H. C. (2015). Women leading education across the continents: Overcoming the barriers. Rowman and Littlefield.

- Thompson, M. C. (2015). Saudi women leaders: Challenges and opportunities. Journal of Arabian $\quad$ Studies, 5(1): $15-36$. https://doi.org/10.1080/21534764.2015.1050880

- Tlaiss, H. A. (2014). Between the traditional and the contemporary: careers of women managers from a developing Middle Eastern country perspective. The International Journal of Human Resource Management, 25(20): 2858-2880. https://doi.org/10.1080/09585192.2014.914054

- Varshney, D. (2019). The Strides of the Saudi Female Workforce: Overcoming Constraints and Contradictions in Transition. Journal of International Women's Studies, 20(2): 359-372.

- von Alberti-Alhtaybat, L., and Aazam, S. (2018). Female leadership in the Middle Eastern higher education. Journal of Economic and Administrative Sciences, 34(2): 90-107. https://doi.org/10.1108/JEAS-08-2016-0018 